\title{
Efficacy of Five Different Growth Media on Seedling Emergence and Juvenile Phenology of Monodora myristica (African nutmeg, Ehuru) in the Nursery.
}

\author{
Peter-Onoh, C.A., Obiefuna, J.C., Ngwuta, A. A., Onoh, P.A., Ibeawuchi, I.I., \\ Ekwugha, E. U., Emma-Okafor, L. C., Nze, E. O., Orji, J. O. and Onyeji, E.C \\ School of Agriculture and Agricultural Technology, Federal University of Technology, Owerri.
}

\begin{abstract}
The study investigated the efficacy of five (5) different growth media on seedling emergence and juvenile phenology of Monodora myristica in the nursery. The growth media were sawdust only, equal mixture of topsoil and sawdust (50:50) by volume, topsoil only, standard nursery soil mixture (3:2:1 ratio) and topsoil arranged in-depth with sawdust (50:50) by volume. All the growth media were bagged in the standard perforated (perforated to allow for water drainage) nursery polybags of $27 \mathrm{~cm} \times 25 \mathrm{~cm}$ and laid flat the thickness of $1 \mathrm{~mm}$. The polybags each containing 3 stands of Monodora myristica were arranged in a cluster of bags per treatment and replicated three times. Data on percentage seedling emergence, number of leaves, plant height and leaf area at 4, 6 and 8 weeks after planting were collected. The analysis of variance was carried out using Genestat. The results showed that Monodora myristica seeds sown in sawdust emerged significantly $(P<0.05)$ early. Juvenile growth was significantly enhanced by standard nursery soil mixture (3:2:1) and topsoil in-depth with sawdust arrangements. The seedling vigour further facilitated field establishment of M. myristica at the Crop Genetic Resource Conservation Centre, Federal University of Technology Owerri. Monitoring and evaluation of the field growth pattern of Monodora myristica is in progress.
\end{abstract}

Keywords: growth media, Monodora myristica, nursery, seedling emergence, seeds.

\section{Introduction}

Monodora myristica Dunal is commonly known as African nutmeg. Monodora myristica with names such as Ehuru (Igbo), Ebenoyoba (Edo), Abo lakoshe (Yoruba), belongs to the family Annonaceae. The M. myristica tree can reach a height of $35 \mathrm{~m}$ and $2 \mathrm{~m}$ in diameter at breast height (DBH). It has a clear trunk and branches horizontally. The leaves are alternately arranged, oblong or petiolate and can reach a size of up to 45 $\mathrm{cm} \times 20 \mathrm{~cm}[1]$.

The fruit is a berry of $20 \mathrm{~cm}$ diameter and is smooth, green and spherical and becomes woody at maturity. It is attached to a long stalk which is up to $60 \mathrm{~cm}$ long. Inside the fruit the numerous oblongoid, pale brown, $1.5 \mathrm{~cm}$ long seeds are surrounded by a whitish fragrant pulp. The odour and taste of the M. myristica seed is similar to nutmeg and it is used as a popular spice in the West African cuisine [2]. The fruits are collected from wild trees and the seeds are dried and sold whole or ground to be used in stews, soups, cakes and desserts [1].

Spices are plant products used in flavouring foods and beverages, including culinary herbs seasonings and condiments of vegetable origin [3]; [4]. They have nutritional value and often referred to as food accessories or adjuncts because of their ability to stimulate appetite and increase the flow of gastric juice [5]. Each spice has a unique aroma and flavour which are derived from compounds known as phytochemicals [6].

Nigeria's biodiverse rainforests in Southeastern Nigeria are disappearing at an even faster rate due to the increased pressure on the ecosystem, as a result of the increase in Nigerian population (140 million) [7]. Some of the valued forest tree spices are facing the threat of extinction caused by high rates of urbanization, deforestation, increasing mobility, and development of new housing schemes which resulted in the large-scale destruction of the natural forests that are rich sources of plants used as spices locally [7].There is need for preservation of endangered spice species as Monodora myristica to avoid total extinction. Environmental protection will be achieved through the planting of tree crops to control the menace of flood and land degradation that has taken over Southeastern Nigeria.

However, nursery operations in Nigeria are in most cases done casually [8], with the result that some practices degrade and retard the growth and quality of seedlings. Good production of permanent tree crop seedlings in the nursery phase is highly influenced by the nursery soil used. The performance of seedlings in the main field is determined by their performance in the nursery [9]; [10]. Nursery soil mixtures have been found to influence the quality of seedlings produced ([11]; [12];[10]). Based, on the foregoing, it becomes necessary to find out the most appropriate nursery medium to enhance seed emergence and seedling growth in the nursery and subsequent field establishment, growth and yield of Monodora myristica. This study investigated the 
efficacy of five different growth media on seedling emergence and juvenile phenology of Monodora myristica in the nursery.

\section{Materials and Methods}

The experiment was conducted in 2011 at the Teaching and Research farm of the Federal University of Technology Owerri Imo state, located between Latitudes $4^{0} 40$ and $8^{0} 15 \mathrm{~N}$, and Longitude 640 and $815 \mathrm{E}$ [13]. It is of the humid tropics with bimodally-distributed annual rainfall of about $2500 \mathrm{~mm}$. The soil is a sandy loam, and earlier classified as an ultisol [14], who further stated that "Soils were derived from Coastal Plain Sands. Five (5) growth media constituted the treatments; they were : sawdust only, equal mixture of topsoil and sawdust (50:50) by volume, rich topsoil only, standard nursery soil mixture (3:2:1 ratio) as control and topsoil in-depth with sawdust arrangement (50:50) by volume (topsoil was used in filling the lower while sawdust was used in filling the upper half of the bag). All the growth media were bagged in the standard perforated nursery polybags of $27 \mathrm{~cm} \times 25 \mathrm{~cm}$ and the thickness of $1 \mathrm{~mm}$. The polybags were arranged in clusters of five (5) per treatment in three replicates. The filling of the nursery bags was done by the use of a hand trowel and shovel. Each polybag was sown with three seeds of Monodora myristica.

The fresh fruits were harvested from healthy stands of protected Monodora myristica in Umuahia with latitude of $05^{\circ} 31^{\prime} \mathrm{N}$ and longitude $07^{\circ} 29^{\prime} \mathrm{E}$. The fruits were kept under shade, allowed to soften for easy processing and water washed to remove the pulp and dried under room temperature before sowing. The phenological developments were monitored. Data on percentage seedlings emergence, number of leaves, plant height and leaf area at 4, 6 and 8 weeks after were collected.

Data analysis was conducted using [15].

\section{1 Results}

\section{Results and Discussion}

Growth media showed significant $(\mathrm{P}<0.05)$ effect on seedling emergence of Monodora myristica seeds (Table 1). Most seeds of M. myristica emerged in sawdust (68.2\%) with variations among other treatments. The least mean value $(37.50 \%)$ was recorded in topsoil followed by topsoil/sawdust mixture (50:50). Results (Table 1) at 4 and 6 weeks after emergence indicated that plant height was not significantly $P<0.05$ affected by various growth media. Sawdust consistently produced dwarf plants when compared with other treatments. At 8week after emergence, growth media showed significant effect on plant height. Standard nursery mixture (3: 2: 1) produced the tallest plants $(15.56 \mathrm{~cm})$, followed by sawdust/topsoil in-depth $(50: 50$ sawdust and topsoil) growth media. Plants grown in topsoil/sawdust mixture were significantly taller $13.99 \mathrm{~cm}$ than those grown in the sawdust only $(10.59 \mathrm{~cm})$ and topsoil $(11.44 \mathrm{~cm})$, respectively.

Leaf area at 4 and 6 weeks after emergence respectively were not significant on different types of growth media (Table 2). However, at 8 weeks after emergence leaf area value significantly $(\mathrm{P}<0.05)$ among different growth media. Sawdust medium recorded significantly very narrow leaves among other treatments while standard nursery soil and sawdust/topsoil in-depth recorded the broadest leaves. Number of leaves per plant was significantly affected by the growth media treatment at 4 and 6 weeks after emergence at $\mathrm{P}<0.05$ (Table 3). Sawdust treatment consistently recorded the lowest number of leaves at all the periods observed while standard nursery soil consistently recorded the highest number of leaves, followed by topsoil/sawdust 50:50 mixture. At 4weeks after emergence, plants nursed on standard nursery mixture showed significant difference in number of leaves produced over topsoil/sawdust, topsoil and sawdust only respectively. At 6 weeks after emergence, number of leaves was significantly lower at sawdust and topsoil respectively than other treatments. At 8 weeks after emergence, standard nursery soil and topsoil- sawdust in-depth recorded highest number of leaves which are significantly more than those nursed in topsoil and sawdust respectively.

\section{2 Discussion}

Nursery soil mixtures have been found to influence the quality of seedlings produced [12]. It is therefore necessary to find suitable nursery soil mixtures/types that will enhance germination and seedling vigour of M. myristica in the nursery. Sawdust improved early and high number of Monodora myristica seedling in the nursery. This finding confirms the efficacy of wood residues (i.e., sawdust and bark) which have been successfully used in containers for growing ornamentals ([16]. The reason could be that sawdust is much lighter in weight than soil and provides high water-holding capacity, good aeration and stimulates warmth which facilitates germination. Wood residues contain all the minor elements essential to plant growth [17]. Sawdust only and topsoil could not give a good result compared to standard nursery soil and sawdust /topsoil in-depth, respectively. Organic matter in the soil mixture determines nutrient and water availability for agricultural productivity. This is in line with [8] who reported that organic manure enhances seedling production. Increase in leaf area and number of leaves development of plants is a function of soil nutrient availability as shown in the result (Table 2). When the soil is rich in organic manure it improves the general performance of plant growth. 


\section{Conclusion and Recommendations}

Standard nursery soil (3:2:1, topsoil: poultry: river sand) seemed to be the appropriate growth media for the nursery of tree crops such as Monodora myristica where seedlings last more than one year in nursery. Sawdust enhances early germination of seeds but should be used for those crops that are transplanted within 4 weeks after planting. Wood residues contain all the minor elements essential for plant growth. However, by nature, it is low in mineral nutrients. Finally, appropriate nursery medium as the standard nursery medium mixture facilitates seedling vigour which determines field establishment.

Table 1. Effect of five growth media on \% seedling emergence of Monodora myristica and plant height

(cm) at 4, 6 and 8 weeks after emergence respectively.

\begin{tabular}{lllll}
\hline Growth media & \% Seedling emergence & 4 & 6 & 8 (wks) \\
\hline Topsoil/sawdust mixture (50:50) & 41.70 & 6.62 & $\mathbf{8 . 5 3}$ & 12.21 \\
Sawdust only & 68.20 & 5.65 & 6.59 & 10.59 \\
Standard nursery soil mixture (3:2:1) & 60.80 & 6.84 & $\mathbf{8 . 1 1}$ & 15.56 \\
Topsoil/sawdust in-depth & $\mathbf{5 0 . 1 0}$ & 7.58 & 9.32 & 13.99 \\
Topsoil & 37.50 & 6.36 & 7.94 & 11.44 \\
LSD $_{0.05}$ & 16.30 & NS & NS & 2.00 \\
\hline
\end{tabular}

NS=Not significant; LSD $=$ Least significant difference.

Table 2. Effect of five growth media on leaf area $\left(\mathrm{cm}^{2}\right)$ of Monodora myristica at 4,6 and 8 weeks after

Leaf area $\left(\mathrm{cm}^{2}\right)$ weeks after emergence emergence

\begin{tabular}{llll}
\hline Growth media & 4 & 6 & $\mathbf{8}($ wks $)$ \\
\hline Topsoil/sawdust mixture $(50: 50)$ & 24.60 & 30.80 & 32.00 \\
Sawdust only & 15.10 & 19.90 & $\mathbf{2 0 . 0 0}$ \\
Standard nursery soil mixture $(3: 2: 1)$ & 24.70 & 26.80 & 35.90 \\
Topsoil/sawdust in-depth & 27.50 & 30.50 & 34.70 \\
Topsoil only & 26.30 & 28.70 & 33.90 \\
LSD $_{0.05}$ & NS & NS & $\mathbf{5 . 6 0}$ \\
\hline
\end{tabular}

NS=Not significant; $L S D=$ Least significant difference.

Table 3. Effect of five growth media on number of leaves of Monodora myristica at 4, 6 and 8 weeks after emergence Number of leaves (weeks)

\begin{tabular}{llll}
\hline Growth media & 4 & 6 & 8 (wks) \\
\hline Topsoil/sawdust mixture $(50: 50)$ & 2.76 & 3.13 & 3.41 \\
Sawdust only & 2.45 & 2.46 & 2.63 \\
Standard nursery soil mixture $(3: 2: 1)$ & 2.89 & 3.85 & 3.56 \\
Topsoil/sawdust in-depth & 2.60 & 3.16 & 3.34 \\
Topsoil only & 2.50 & 2.71 & 2.60 \\
LSD $_{0.05}$ & 0.26 & 0.28 & 0.46 \\
\hline
\end{tabular}

LSD= Least significant difference.

\section{Reference}

[1]. Weiss, E.A., 2002 .Spice crops, in Spice crops. 2002. Workshop on Slash/Mulch Production Systems. Turrialba ,Costa.

[2]. Louise, M.D. 2002; Spices, Exotic Flavours and Medicines. Biomedical Library. UCLA. p. 1.

[3]. Sigmund, R and Gustar, E .1991. The cultivated Plants of the Tropics and Subtropics .P.276.

[4]. Govindarajan, V. S. 1985. CRC Critical Reviews in Food Science and Nutrition .22, 109-176.

[5]. Dziezak, J.D, 1989. J. Food Technology, 43(1): 102-116

[6]. Walker.J.R.L.1994. Antimicrobial compounds in food plants. pp 181-204.

[7]. Adelaja, B. A and Fasidi, I. O. 2008 Survey and collection of indigenous spicegermplasm for conservation and genetic improvement in Nigeria Bioversity International - FAO Published in Issue No.153, page 67 to 71 . early seedling growth of two tropical tree species. Moor Journal of Agricultural Resources 4 (2): 6-65

Baiyeri, K.P., 2003. Evaluation of nursery media for seedling emergence and growth and yield of spinach. Nigeria Agricultural Journal: 35-38.

Adeyefa, C.A., 1991. Effect of age of seedling and frequency of cutting on Gongronema latifolia (Beuth) stem cutting in different rooting media. Africa Journal of Biotechnology 5: 425-428.

[11]. Obiefuna,J.C., I.I. Ibeawuchi, K.P. Baiyeri and C.A. Obiefuna (2012). Field Experimentation and Communication for Agricultural Development. DFC Publishers, Owerri. ISBN: 976-976-979-810-5, p. 142.

Baiyeri, K.P and Ndubizu, T.O.C., 1994.Variability in growth and field establishment of false horn plantain suckers raised by six cultural methods. Museum for Africa 4:1-3.

[13]. FDALR (Federal Department of Agricultural Land Resources) 1985.The reconnaissance Soil survey of Imo state (2: 250). Soils Report. Pp 133.

[14]. Orajaka, S.O 1975. In Ofomata G.E.K (ed) Nigeria in maps; Eastern states. Ethiopia Publ. House, Benin City. Pp 5-7.

[15]. Genestat Release Edition 3. 2007. Free version of Statistical package. Htt://discovery.genestat.co.uk

[16]. Gartner, J.B., M.M. Meyer, Jr., and D.C. Saupe., 1971. Hardwood bark as growing media for container grown ornamentals. Forest Prod. J. 21:25-29. 
Efficacy of Five Different Growth Media on Seedling Emergence and Juvenile Phenology...

[17]. Owston, P.W., 1973. Cultural techniques for growing containerized seedlings. Western For. Nursery Counc. and Intermountain For. Nurseryman's Assoc. Proc. 1972:32-41. 